\title{
O MÉTODO DE RORSCHACH E A PSICOPATOLOGIA FENÔMENO-ESTRUTURAL*
}

\author{
THE RORSCHACH METHOD AND THE \\ PHENOMENO-STRUCTURAL PSYCHOPATHOLOGY
}

Anna Elisa de Villemor AMARAL ${ }^{1}$

\begin{abstract}
RESUMO
O método de Rorschach foi, desde sua criação, centro de importantes investigações em psicopatologia. Por tratar-se de um método de estudo da personalidade baseado na análise de respostas a estímulos não estruturados, serve de base para a observação dos fenômenos psíquicos complexos relacionados com os processos de percepção, associação, projeção, e também da comunicação e expressão verbal. Daí provêm a riqueza das análises feitas sobre o material coletado, a profundidade e o alcance das observações e conclusões obtidas e a diversidade de metodologias empregadas para tal fim. Dentre os diversos sistemas de análise e interpretação desenvolvidos e bastante em uso, embora menos conhecida em nosso país, encontra-se a metodologia fundamentada nos princípios da Psicopatologia Fenômeno-estrutural, baseada no estudo da linguagem e da visão em imagens. Sua contribuição para a compreensão do funcionamento normal e patológico é bastante significativa e, sendo assim, o objetivo deste artigo é contribuir para a difusão dessa teoria e desse método de análise, demonstrando sua riqueza para a compreensão diagnóstica do indivíduo.
\end{abstract}

Palavras-chave: Rorschach; avaliação psicológica; psicopatologia fenômeno-estrutural; psicodiagnóstico; psicopatologia.

\begin{abstract}
The Rorschach method is a source of several studies in psychopathology due to its origins and foundations. It constitutes a method for personality
\end{abstract}

(*) Este trabalho é parte do relatório de pós-doutorado realizado na Universidade da Savóia (França) com financiamento da FAPESP.

(1) Doutora do Programa de Estudo Pós-Graduação em Psicologia da Universidade São Francisco. Endereço para correspondência: Rua: Alexandre Rodrigues Barbosa, 45 - Itatiba/SP Cep: 13251-900.

E-mail: anna.villemor@saofrancisco.edu.br. 


\begin{abstract}
assessment based on the responses given to non structured stimulus which allows the observation of complex psychological phenomena related to perception, association, projection and the verbal expression. This fact permits the various methodologies of analysis developed all over the world, each point of view with its scope and importance. Among the several systems we can found the method based on the Phenomeno-structural psychopathology that proceeds with the analysis of the language and the imagery, bringing important contribution for the comprehension of the normal and the pathological functioning. The purpose of this article is to contribute to the diffusion of this theory and this method in our country, showing it's value for the psychological assessment.
\end{abstract}

Key words: Rorschach; psychological assessment; psychopathology phenomeno-structural; psychodiagnostic; psychopathology.

O método de Rorschach, dados a sua origem e os seus fundamentos, vem sendo desde sua criação fonte de inúmeros estudos, constituindo-se o centro de importantes investigações em psicopatologia. Por tratar-se de um método de estudo da personalidade baseado na análise de respostas a estímulos não estruturados, serve de base para a observação dos fenômenos psíquicos complexos relacionados com os processos de percepção, associação, projeção, e também da comunicação e expressão verbal. Daí provêm a riqueza das análises feitas sobre 0 material coletado, a profundidade e o alcance das observações e conclusões obtidas e a diversidade de metodologias empregadas para tal fim.

Dentre os diversos sistemas utilizados de análise e interpretação do Rorschach, há um menos conhecido e empregado em nosso país, que tem, porém, maior aceitação em países europeus, destacadamente a França, seu país de origem. Trata-se da metodologia fundamentada nos princípios da Psicopatologia Fenômenoestrutural, baseada no estudo da linguagem e da visão em imagens, cuja contribuição para a compreensão do funcionamento normal e patológico é bastante significativa. O objetivo deste artigo é contribuir para a difusão dessa teoria e desse método de análise, demonstrando sua riqueza para a compreensão diagnóstica do indivíduo. Abordaremos inicialmente as origens do método num breve histórico para, a seguir, demonstrar suas implicações teóricas com relação à psicopatologia e ao desenvolvimento e, finalmente, salientar as diferenças e especificidades dessa abordagem em relação às outras mais conhecidas em nosso meio.

\section{BREVE HISTÓRICO}

A Psicopatologia fenômeno-estrutural desenvolveu-se nas décadas de 20 e 30 quando Eugène Minkowski realiza diversos estudos em psicopatologia e publica suas duas principais obras: La squizophrenie em 1927 e Le temps vécu em 1933. Em suas observações dos doentes mentais, e particularmente dos esquizofrênicos, Minkowski (1927, apud Barthelemy, 1996) percebe a importância da fala e da linguagem como meio de expressão dos distúrbios a que estavam sujeitos. Registrava suas palavras textualmente e assinalava as passagens mais características de seu discurso para observar os problemas essenciais dos distúrbios que os afetavam, registrando assim os mecanismos preponderantes da doença tal como experimentados pelos pacientes. Influenciado por Bergson, que fez a distinção entre tempo vivido como experiência interna em contraposição ao tempo cronológico-mensurável-, desenvolveu pesquisas a partir dessas noções. Para Minkowski, as alterações do tempo vivido nos pacientes podem ser captadas por meio de uma fenomenologia da linguagem. Considerada como um dos elementos principais de nossa função expressiva, a 
linguagem nos permite captar as alterações do tempo vivido nos pacientes e mais amplamente as características do tempo vivido por cada um de nós. Esse autor parte então do estudo da linguagem corrente e de suas metáforas para verificar as qualidades de espaço e tempo expressas pelas marcas e inscrições espaçotemporais da experiência vivida.

Francisca Minkowska, em torno de 1938, toma contato pela primeira vez com o Método de Rorschach e inicia suas pesquisas apoiada nos estudos de Minkowski. Seu principal interesse então referia-se à genealogia dos doentes psiquiátricos. Nessa época Minkowska trabalhava na equipe de Bleuler e teve a oportunidade de estudar seis gerações de dois irmãos hospitalizados em seu serviço. Estudando de forma direta, e por meio de seus descendentes, as particularidades psicológicas dessa família, Minkowska encontra dois ramos importantes: 0 primeiro condizia com as hipóteses de Bleuler e com o caminho indicado por ele; mas o segundo, em vez de conduzi-la em direção aos transtornos do tipo maníaco-depressivo conforme Bleuler havia sugerido, a coloca em face do inesperado fenômeno da epilepsia. Afastando-se do interesse específico para a doença, Minkowska sente-se mais atraída pelas características daqueles que nessa família não demonstravam transtornos mentais mas apresentavam características de personalidade comuns. Assim, numa família com alguns casos de epilepsia ela encontra indivíduos com a "afetividade concentrada, condensada, viscosa, que adere e não se desliga facilmente dos objetos do ambiente, mesmo que as circunstâncias assim o exijam". Denomina de epileptóide o indivíduo com uma personalidade em que predomina a afetividade viscosa e sem mobilidade, por oposição ao que Kretchmer nessa mesma época havia denominado de esquizóide (Barthelemy, 1996).

Nesse momento, Minkowska adquire sua convicção a respeito do contraste entre dois grandes princípios da organização da estrutura mental, que encontram seus extremos nos mecanismos dominantes de dois pólos: o da epilepsia e o da esquizofrenia. Tendo conheci- mento sobre o método psicodiagnóstico criado por Rorschach e associando-o aos ensinamentos de Minkowski sobre a análise da linguagem, essa autora procura dar continuidade à exploração das tendências sensoriais ou, mais propriamante, sensório-motoras.

Diferentemente de Rorschach, que quando criou seu método diagnóstico estava fundamentalmente interessado em estabelecer a relação entre traços de personalidade e as características perceptivas, Minkowska vai em busca, por meio da linguagem meticulosamente registrada na fala do paciente, dos mecanismos que possam aproximá-lo de um dos dois pólos considerados por ela. Assim como Bleuler denomina de cisão ou spaltung o mecanismo essencial que caracteriza a esquizofrenia, a autora identifica o mecanismo da ligação ou lien, responsável por uma visão rica em imagens e pela tendência em unir partes da figura que aparecem isoladas para outras pessoas. A ligação é responsável pela criação de conjuntos e combinações progressivas mais ou menos coerentes e sua preponderância é tanto maior quanto maior for a proximidade do indivíduo ao pólo epilepto-sensorial. Assim como na imagem, encontramos na linguagem expressões mais ou menos marcadas pela ligação, seja no uso de expressões combinadas em que as palavras indicam forte proximidade com os elementos sensoriais - ligação direta e concreta com a realidade e com o mundo exterior -, seja pela ação expressa por mímicas e movimentos durante o exame. Palavras que indicam objetos concretos são mais carregadas de elementos sensoriais e portanto expressam o mecanismo de ligação enquanto as palavras com maior nível de abstração são mais racionais e mais impregnadas de cisão ou corte - coupure - para utilizar o termo escolhido por Minkowska. Como exemplo podemos considerar o uso, por um paciente, da palavra leão na prancha $\mathrm{VIII}$, que se refere a um objeto concreto ou o uso do termo quadrúpede por outro paciente na mesma prancha, com características mais abstratas e racionais.

Desse modo, a análise das respostas no Rorschach só é possível desde que estas tenham sido anotadas exatamente como foram pronun- 
ciadas, evitando-se mesmo as abreviações. A presença do artigo, e mesmo das hesitações e incoerências no uso dessa partícula do discurso, pode ser reveladora de características de personalidade que passariam despercebidas por outros métodos de análise. Uma frase dita por um paciente que contenha poucos artigos e em que os substantivos predominam tem um caráter mais esquemático e recortado do que uma frase na qual aparecem mais elementos de ligação, dando-lhe um caráter mais contínuo. Assim, preposições, contrações, reticências, repetições são todas particularidades da linguagem que expressam níveis distintos de sensorialidade ou racionalidade, verificando-se no pólo sensorial o predomínio do concreto e no pólo racional o predomínio do abstrato.

De maneira semelhante, o comportamento durante o exame e a relação com o examinador também trazem a marca da sensorialidade ou da racionalidade, dependendo da maior ou menor distância existente entre sujeito, material de exame e aplicador. Neste caso, quanto maior for a proximidade entre esses três elementos, maior será a intensidade da ligação. Indivíduos sensoriais se movimentam mais ao fazer a prova, fazem mais mímicas, manipulam mais o material, tocam e se dirigem diretamente ao aplicador com freqüência, ao passo que os indivíduos com inclinações predominantemente racionais revelam uma atitude mais distante em relação ao contexto de exame.

Portanto, para Minkowska, as palavras no Rorschach não são apreendidas nem em relação ao seu conteúdo específico, nem em relação a um significado simbólico latente, mas são consideradas em virtude de situações vitais a que elas se referem. Trata-se dos fundamentos de uma semântica, trata-se de verificar na linguagem o que ela traz de imagens, movimentos, sensações, disposições afetivas em relação às fontes relacionais e propensões expressivas - sua dimensão metafórica. A análise então se apóia num procedimento bastante minucioso, no dissecar palavra por palavra e estabelecer as expressões de base aí contidas. O que se manifesta então não são conteúdos que simbolizam conflitos psíquicos relacionados com os impulsos de vida ou de morte, como se diria numa abordagem psicanalítica, mas princípios de ordem estrutural relacionados com o espaço e o tempo vividos. Mesmo correndo o risco de fazer reduções simplistas ao darmos exemplos, poderíamos tentar ilustrar as diferenças considerando, por exemplo, que, se numa análise de fundamentação psicanalítica poderíamos centrar a ênfase na interpretação da resposta 'arma pré-histórica' enfocando seu conteúdo agressivo e primitivo, na análise fenômeno-estrutural estaríamos mais interessados na esquematização da frase, na ausência de aspectos sensoriais na linguagem e no distanciamento no tempo que refletem um funcionamento esquizo-racional. Entretanto, embora essas diferenças sejam significativas, não se pode acreditar ingenuamente que uma ou outra abordagem não leve em conta os aspectos abordados pela outra, embora com ênfases distintas.

É, portanto, por meio do Rorschach que Minkowska toma em consideração os mecanismos essenciais, inscritos no núcleo da expressão pela linguagem e inferidos da prática clínica. Corte e ligação traduzem em profundidade as características da relação do indivíduo com o mundo e o estudo da linguagem permite apreender o enraizamento temporo-espacial do indivíduo. Em cada um dos pólos representados num extremo pelo corte e noutro pela ligação nos defrontar com um mundo mental em que predomina a desintegração ou a aglutinação, respectivamente.

\section{PSICOPATOLOGIA E DESENVOLVIMENTO}

Há oposição entre os dois pólos - sensorial e racional - o primeiro que representa maior proximidade com a realidade e o segundo, maior distanciamento com a realidade concreta. No pólo racional, que tem sua expressão máxima na esquizofrenia, encontram-se mais abstrações e maior distanciamento da experiência concreta, enquanto no pólo sensorial, cuja expressão extrema está na epilepsia, encontra-se a 
sensorialidade e a adesividade. Para Ganidel (1960), o mundo racional é marcado pela horizontalidade, pela imobilidade, por retidão e simbolismo, enquanto o mundo sensorial, pela verticalidade, movimento, a linha sinuosa e a metáfora. Minkowski (apud Helman, 1983) já havia chamado a atenção para as diferenças entre o vago e o confuso, alertando que o primeiro caracteriza o funcionamento racional e o segundo é observado no funcionamento sensorial. Delaunay (1977) aponta as distinções no universo da ficção entre uma produção mais sensorial ou mais racional. Nesse sentido, esse autor diferencia o feérico do fantástico e argumenta que o feérico constitui um universo mais coerente, impregnado de imaginação sensorial que não atinge o sentimento do real, enquanto o fantástico é mais fragmentado e nele o imaginário pode romper mais agudamente com a realidade.

O mecanismo de ligação é responsável tanto pelo fenômeno patológico de aglutinação de imagens e pensamentos quanto por contribuir, de modo importante, para os processo de integração e compreensão da experiência vivida. Sendo o mecanismo de ligação responsável tanto pela aglutinação quanto pela integração, somos naturalmente levados a considerá-lo, do ponto de vista da teoria psicanalística, um importante representante da posição depressiva na qual se realiza a integração do objeto, passo fundamental para a saúde mental. De fato, a depressão é um dos quadros nos quais a ligação pode se manifestar (Barthelemy, 1992), sendo a integração o resultado de ligações bem sucedidas. Entretanto, a ligação em si não necessariamente resulta em integração, podendo, ao contrário, originar imagens sobrepostas, aglutinadas ou fundidas, de modo bastante bizarro e confuso. O excesso de aglutinação gera aumento da tensão que conduz a rupturas bruscas que, no seu extremo, caracterizam as crises epiléticas.

Diversos autores demonstraram a presença e a evolução desses mecanismos nos quadros psicopatológicos, entre os quais se destacam: Wawrzyniak (1982), em seu estudo sobre adolescência e suas aproximações com a psicose; Ternoy (1998), em suas pesquisaas sobre a alucinação; Barthelemy et Viala (1993), em seu trabalho sobre os processos orgânicos deficitários; Yazigi (1994), em seu trabalho sobre a epilepsia, e Amparo (2002), na sua investigação com pacientes esquizofrênicos.

Para além da psicopatologia, identificamos, no curso do desenvolvimento, etapas em que predomina ora a sensorialidade, ora a racionalidade e que podem ser observadas e acompanhadas pelos mesmos mecanismos essenciais de ligação e corte. Assim é que, nos casos de crianças, se observa um predomínio da sensorialidade, sobretudo entre 3 e 6 anos, quando a partir de então os mecanismos racionais começam a dominar e têm sua participação fundamental para a escolarização.

Tal desenvolvimento também pode ser observado no curso de tratamentos psicopatológicos. Helman (1971) demonstra como nas diversas patologias e transtornos psíquicos podemos acompanhar a evolução de uma poussée sensori-motrice ou, como chamaremos daqui por diante, ímpeto sensório-motor, que representa uma maior integração do pensamento e um maior contato com a realidade no caso de pacientes graves. De modo contrário, Barthelemy $(1987,1993)$ observa, no tratamento de pacientes alcoólicos e no processo de "desmame" (abandono do hábito de beber), o caminho inverso percorrido de um extremo em que domina a sensorialidade e a viscosidade no período de intoxicação para um direcionamento mais marcado pela racionalidade durante a desintoxicação.

Retomando, no desenvolvimento normal há etapas nas quais predomina a sensorialidade e outras em que encontramos maior racionalidade. As crianças são mais sensoriais que os adultos, mas quando chegam à idade de seis e sete anos precisam se tornar mais racionais para poder aprender, caso contrário terão menores condições de se manterem sentadas, pensando, pois predominará o movimento, a necessidade de experienciar concretamente cada fenômeno ao seu redor. Se a criança não consegue afastar-se da sensorialidade, não conseguirá aprender. 
Assim, os dois pólos constituem uma tipologia, mas ao mesmo tempo representam etapas evolutivas que se alternam. Seja qual for a tipologia dominante em uma pessoa, há momentos mais sensoriais e mais racionais em todas, variando seja de acordo com estados mais patológicos, seja por causa da evolução normal. Daí ser interessante estudar o ímpeto sensório-motor, o que nos dá a possibilidade de verificar como em um determinado período uma pessoa evolui entre os dois pólos, desenvolvendo possibilidades mais ou menos adaptativas. Nesses estudos acompanha-se, por meio do Rorschach, a produção do indivíduo em diferentes períodos.

Como já mencionamos, a linguagem permite verificar os mecanismos essenciais de ligação e corte presentes no universo representacional de um indivíduo, abrindo-nos o caminho para suas relações com o espaço e o tempo vividos e, portanto, para sua estrutura mental. Os estudos sobre lingüística explicitam as relações entre o mundo mental e a linguagem. Guillaume (1973) afirma que a linguagem torna o mental algo físico, na medida em que pode ser apreendido pelos sentidos, e que a observação da ciência da linguagem torna visível o que seria inacessível de outra maneira. A linguagem é a expressão física do mental, pois torna o mental captável por meios sensoriais, seja pela visão, seja pela audição. Mas mesmo assim, a linguagem será sempre uma representação 'fisificada' do mental, jamais sendo absolutamente fiel ao mental que ela representa. Nesse sentido, Guillaume (1973) considera a linguagem humana uma estrutura ou uma arquitetura que busca continuamente um ajustamento ótimo ao mental e que apenas existe a partir do momento em que o vivido experimental é transformado em representação, sendo, contudo, nada mais que um trompe l'oeil do que é a mente em sua essência. Conforme Bérgson (apud Guillaume, 1973, p 138), do ato da linguagem só temos acesso aos seus últimos momentos, pois antes disso há um momento prévio no qual se estabelece um contato entre o pensamento em instância de expressão e a língua da qual o espírito tem a posse permanente.
Encontramos em Guillaume (1973), mas Rousseau (1990), já havia mencionado anteriormente a idéia de que, seja no sentido ontológico ou no do desenvolvimento da espécie humana, o nível de evolução da linguagem é sempre expressão de progresso, seja da pessoa, seja da civilização. Tanto num sentido como no outro, a linguagem é representação de um pensamento, que por sua vez é conquista e desenvolvimento a partir de um estágio de turbulência mental. Há uma relação dialética entre pensamento e linguagem, um se desenvolvendo calcado no desenvolvimento do outro e para Guillaume (1973) "a linguagem traz ao pensamento o poder de salvaguardar o poder adquirido, o seu estado construído e de aumentar esse poder" (p. 246).

Se, por um lado, na abordagem psicanalítica a ênfase na análise das respostas dadas ao Rorschach focaliza seu conteúdo e seu simbolismo e a fala do paciente importa tanto ou mais que a codificação das respostas, por outro lado, não se busca uma estrutura da linguagem enquanto fenômeno mental, mas sim o sentido simbólico contido em cada conteúdo enunciado.

A diferença entre o sistema de análise com referencial psicanalítico e o da psicopatologia fenômeno-estrutural localiza-se, mais precisamente, na diferença existente entre metáfora e símbolo. Para a psicopatologia fenômeno-estrutural, a metáfora é a expressão indireta de objetos ou sentimentos em seus componentes mais concretos e sensoriais, ao passo que o símbolo está ligado às abstrações intelectuais. Isso nos permite classificar a metáfora como algo ligado à sensorialidade e o símbolo como algo ligado à racionalidade. Em psicanálise, a dimensão simbólica reflete os registros das experiências emocionais em relação aos objetos, aos impulsos, à sua satisfação ou às proibições a eles impostas. Mas sabemos que, para uma análise efetiva do universo simbólico, é necessário que o produto a ser analisado provenha de uma mente desenvolvida, com capacidade de simbolização, já que esta não está presente em todos os indivíduos, sendo falha em patologias graves. Pacientes mal mentalizados, como diria P. Marty 
$(1998)^{2}$, praticamente não produzem símbolos traduzíveis, o que torna o alcance das análises simbólicas mais limitado nestes casos. Já a metáfora ou a estrutura da linguagem pode ser analisada independentemente, sendo sempre acessíveis do nível de desenvolvimento mental, quando há comunicação verbal.

\section{DIFERENÇAS METODOLÓGICAS}

São muitas as diferenças entre essa abordagem e outras correntes atualmente aceitas e mesmo entre a abordagem da psicopatologia fenômeno-estrutural e o princípio original de análise criada por Hermann Rorschach. As diferenças começam pelo sistema de codificação da resposta, que tem para as abordagens mais difundidas do Rorschach um papel mais fundamental do que para os adeptos da proposta de Minkowska. Para estes, embora a classificação tenha seu lugar de importância, esta não supera o que a análise da linguagem possa trazer de contribuição para a compreensão do universo mental do indivíduo. Nesse sentido, para a psicopatologia fenômeno-estrutural, os códigos atribuídos às respostas são considerados principalmente por permitirem a identificação das caracteísticas da percepção e da visão em imagens, sendo raramente considerados do ponto de vista quantitativo.

As diferenças entretanto não se restringem à importância dada à classificação das respostas, estendendo-se à maneira mesmo de classificá-las, variando a importância dada exclusivamente ao que é dito pelo paciente, no caso do Sistema Compreensivo, ou no que pode ser inferido de sua fala, segundo o que ensina Minkowska. Por exemplo, para o Sistema Compreensivo, ou para as principais escolas de Rorschach no mundo atual, uma resposta de cor só é classificada como tal desde que o indivíduo faça referência explícita à inclusão da cor na formação do percepto. No entanto, para os seguidores de Minkowska (Barthelemy, 1987), uma resposta deve receber o código de cor sempre que seja dada em uma área colorida e que o objeto referido possua aquela cor. Do mesmo modo, encontramos diferenças significativas no que diz respeito à classificação das respostas de movimento, estando as subcategorias de movimento distribuídas de forma distinta, principalmente nas respostas de claro/escuro e sombreado.

Além disso, H. Rorschach, ao criar o seu teste, parte de uma visão psicopatológica que pressupõe a existência de uma tipologia psíquica, na qual se encontram dois tipos básicos: o introversivo e o extratensivo, caracterizados, respectivamente, pela supremacia de repostas de movimento ou de cor. Essa tipologia se manteve nas principais abordagens atuais, mas não é compartilhada pelos adeptos da Psicopatologia fenômeno-estrutural, sendo a tipologia proposta por Minkowska e Helman bastante oposta, na medida em que identifica os tipos epilepto-sensorial e esquizo-racional caracterizados, num extremo, pelas respostas de Movimento e Cor e, no outro, pelas respostas de Forma.

Desse modo, podemos esquematizar da seguinte maneira as duas tipologias descritas de acordo com os dois métodos de análise:

$$
\begin{array}{cc}
\text { A - Para Hermann Rorschach } & \\
\text { Introversão } & \times \text { Extratensão } \\
\downarrow & \downarrow \\
\text { Movimento } & \text { Cor } \\
\text { B - Para Francisca Minkowska } \\
\text { Epilepto-sensorial } \\
\downarrow \text { Esquizo-racional } \\
\text { Movimento e Cor } & \downarrow \\
& \text { Forma }
\end{array}
$$

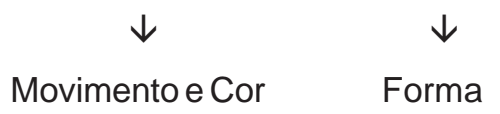

Nesse caso, observa-se que a diferença fundamental entre as duas abordagens tipológicas reside no papel atribuído às respostas de movimento, principalmente porque na segunda abordagem é retirado do movimento sua ligação

\footnotetext{
(2) Mentalização se refere à quantidade à qualidade das representações mentais que fazem parte do repertório de experiências vividas pelo indivíduo e registradas em sua memória, sendo mais ou menos acessíveis à consciência (Marty, 1998).
} 
com os processos cognitivos em geral e mais especificamente de pensamento, que ficam identificados exclusivamente com as repostas de forma. Movimento e cor, nesta visão, são ambos representantes de um modo de vivenciar o mundo mais concreto e direto com a realidade, estando as repostas de forma mais diretamente relacionadas com a capacidade de abstração e com os processos racionais.

Surge daí uma natural interrogação sobre a existência ou não de contradição entre as duas propostas ou se se trata apenas de duas maneiras de classificarmos as pessoas, como se primeiro resolvêssemos classificá-las segundo determinados critérios - formando dois grupos e depois as classificássemos conforme outros critérios e daí formássemos outros dois grupos, diferentes dos primeiros, uma vez que compostos pelas mesmas pessoas agora distribuídas diferentemente.

No entanto, o problema não é tão simples, pois permanece a dúvida quanto às origens das repostas de movimento. Incluí-las no pólo da sensorialidade implica afastá-las do pólo racional. Para Berthelemy (2003, comunicação pessoal), contrariamente ao que $\mathrm{H}$. Rorschach dizia, as respostas de movimento estão sim presentes nas pessoas mais ativas e propensas a agir e concretizar sua vivência no mundo por meio de ações concretas. Isto se opõe claramente a $\mathrm{H}$. Rorschach quando este afirma que, contraditoriamente, os que dão mais respostas de movimento são os que menos se expressam por meio da motricidade ( $p$ 82). Como então compreender essa contradição apontada por Rorschach? Sabe-se que o movimento é o único determinante que não está na figura e que ver algo em movimento depende dos processos imaginativos projetados no mundo exterior. Tal fato fez com que tradicionalmente as respostas de movimento fossem consideradas representantes do universo interior, do mundo interno com seus recursos imaginativos. Daí as clássicas interpretações sobre as proporções Movimento e Cor para erlebenustypus (tipo de vivência), bem como sobre a proporção W:M, tão tradicional no que se refere às ambições intelectuais e aos recursos criativos. Contudo, para a Psicopatologia Fenômeno-estrutural, as respostas de movimento estão relacionadas à sensorialidade, dada sua origem na experiência proprioceptiva, e não na racionalidade.

Resta-nos indagar o quanto essa visão é oposta à visão mais amplamente aceita, na qual o movimento está relacionado aos processos cognitivos. Primeiramente, podemos considerar racional como parte do universo cognitivo. Neste caso, pelo fato de o movimento não estar nas figuras que compõem o material do Rorschach, nos colocaria mais à distância da experiência imediata e em relação à experiência já vivida transformada em registros mentais evocáveis durante a percepção que, portanto, não fazem parte da percepção direta, mas são agregados posteriormente ou mesmo simultaneamente por um processo de associação entre a percepção vivida no presente, distante do estímulo apresentado, e os registros do que já passou mas que foram bem mentalizados.

As respostas de movimento possuem então essa dupla subordinação: estando em relação às vivências proprioceptivas podem ser representantes do universo sensorial, mas uma vez que não fazem parte dos elementos imediatos da percepção, identificam-se com os registros mentais, que participam ativamente dos processos cognitivos. A questão é intrigante e complexa, e essa indagação fica no momento sem uma resposta definida, constituindo estímulo e desafio para futuras pesquisas.

Concluindo, no Rorschach clássico estão em jogo, no processo de análise, os elementos da percepção que permitem a discriminação de formas associadas a outros elementos que a elas se agregam, ao passo que na análise fenômeno-estrutural buscam-se os elementos do mundo mental expressos pela linguagem, que refletem a estrutura do pensamento e, em última análise, da mente. Seja pelo caminho da percepção, seja pelo caminho da expressão pela linguagem, o objetivo é apreender o universo mental do indivíduo e sua estrutura, organizações mais ou menos patológicas, de modo a orientar condutas terapêuticas que levem em conta as 
capacidades e limitações de cada um. Poder integrar as diversas contribuições originadas dos vários enfoques representa uma possibilidade de ampliar o conhecimento sobre o indivíduo, otimizando as perspectivas de ajuda.

\section{REFERÊNCIAS BIBLIOGRÁFICAS}

AMPARO, D.M. (2002). A simbolização na esquizofrenia. Um estudo fenômeno-estrutural com o método de Rorschach. Tese de Doutorado, Universidade de Brasília, Brasília.

BARTHELEMY, J-M (1987) L'analyse phénomeno-structurale dans l'étude psychologique des alcooliques. L'experience de la cure et l'apport des poétes. Toulouse: Erès.

BARTHELEMY, J-M (1990) La place du Rorschach dans les dévelopments actuels de la psychopathologie phénomeno-structurale. Techniques Projectives II. Montpellier: Sillages.

BARTHELEMY, J-M (1993) Rorschach et Psychopathologie Phénomeno-structurale dans l'étude de l'alcoolisme. Trabalho apresentado nas VII Jornadas Nacionales de Psicodiagnóstico e $\mathrm{V}$ Jornadas Nacionales del Asociación Argentina de Estudios e Investigación en Psicodiagnóstico, Buenos Aires.

BARTHELEMY, J-M (1993) Plainte et contrainte répétitive dans le Rorschach d'alcooliques détériorés. Psychologie médicale, 22 (8) 694-6.

BARTHELEMY, J-M e Viala, M-F (1993) Formes diferentieles d'expression dans le Rorschach dês Processus organiques déficitaires. Trabalho apresentado no XVI International Rorschach Congress, Lisboa.

BARTHELEMY, J-M (1994) Processus, évolution et structure mentale. Bulletin de Psychologie. XLVII (416), 474-6.

BARTHELEMY, J-M (1996) L'analyse du langage dans le Rorschach selon la méthode Phénomeno-structurale. Trabalho apresentado no XV International Rorschach Congress, Boston.

DELAUNAY, P (1977). Rêve eveillé dirigé et analyse phénomeno-structurale. Prolongements dans l'experience mescalinienne de Henri Michaux. Psychopathologie structurale 2. Lille: PUL.

GANIDEL, G. (1960) - Étude sur le langage de Falubert et de Giraudoux. Cahiers du Groupe Françoise Minkowska. Lille:PUL.

GUILLAUME, G. (1973) Principes de linguistique theorique. Quebec: Les Presses de l'Université Laval.

HELMAN, Z (1971) La poussée sensori-motrice. Bruxelas: Dessart.

HELMAN, Z (1983) La vision en image dans la courant de la psychopathologie structurale. Bulletin de Psychologie XXXVI (362), 811-9.

HEMAAN, Z (1984) Délire et vision en image. Psychopathologie structurale 4. Toulouse: Erès.

MARTY, P. (1998) Mentalização e Psicossomática. São Paulo: Casa do Psicólogo.

ROUSSEAU, J.J. (1990) Essai sur l'origine de langues. Paris: Galimard.

TERNOY, M. (1998) Une caracteristique specifique de la vision en image chez l'halluciné: détaillage. Bulletin de Psychologie, 51 (2) 135-41.

WAWRZYNIAK, M. (1982) La déstabilization du sentiment de réalité à la adolescence: étude de Rorschach et réference à une oeuvre poétique de Arthur Rimbaud. Bulletin de Psychologie XXXVI (382) 887-95.

YAZIGI, L. (1994) - A prova de Rorschach, a especialização hemisférica e a epilepsia. Tese de Livre docência. UNIFESP - Escola Paulsita de Medicina, São Paulo.

Recebido para publicação em 13 de outubro de 2003 e aceito em 18 de dezembro de 2003. 
